\title{
Current trends of anatomical physiology of tattoo
}

\author{
Naveen S Kotur ${ }^{1}$, Anitha M R ${ }^{2, *}$, Vijayanath $V^{3}$, Ghansham Sharma ${ }^{4}$ \\ ${ }^{1}$ Department of Physiology, ESIC MC \& PGIMSR, Bengaluru, Karnataka, ${ }^{2}$ Departmrnt of Anatomy, Akash \\ Institute of Medical Sciences, Bengaluru, Karnataka, ${ }^{3}$ Department of Forensic Medicine, ESIC MC \& PGIMSR, \\ Bengaluru, Karnataka, ${ }^{4}$ Department of Community Medicine, ESIC MC \& PGIMSR, Bengaluru, Karnataka
}

*Corresponding Author:

E mail: dranithamr167@gmail.com

\begin{abstract}
Introduction: Remarkable increase in the occurrence of tattoo has triggered to do this study to know the possible reason for this. Presently this has emerged as a big fashion accessary to both the genders.

Objectives: To know the prevalence of tattoo, assess the religion and gender-wise distribution, know the reasons for getting a tattoo and, after effects of tattooing.

Materials and Methods: All the individuals from the society with whom the researcher come in contact having tattoos. A proforma was prepared for the same with the standard questionnaire and asked the individuals to fill the same. The researcher will help in filling the form for illiterates; since the answer to the questions are specific standard replies.

Results and Discussion: Since the study was conducted in a place where the majority of Hindus live and religion may not give any statistical significance with respect to religion. More participants were from urban backup. Almost equal number of individuals used the permanent and temporary methods of a tattoo. And they were found more in hands being done by an amateur with a single colour. Getting the tattoo removed was not seen in the present study and very few have the regrets of having the tattoo done on them.

Conclusion: Here the urban area and literacy rate have some significant comparison with the available literature. In this study students have more tendency compared to another group. And number had a permanent tattoo with a single colour. Hands are the commonest site for tattoo and fashion is the main reason. The amateur done tattoo was more with no complaints after getting the tattoo done. Majority of the people have no plans to get the tattoo removed and less number of subjects were regretting getting the tattoo done.
\end{abstract}

Keywords: Colour, Fashion, Hands, Profession, Removal.

Received: $11^{\text {th }}$ October $2017 \quad$ Accepted: $28^{\text {th }}$ December, 2017

\section{Introduction}

A tattoo is the one which makes body modification; in which the design is made by using inserting dyes, pigments and ink. This may be done either indelible or temporary, into a layer of the skin most of the time. As broad outlook Tattoos can be categorised: decorative, symbolic, pictorial. In $19^{\text {th }}$ century naval routes originally started using these tattoos only in males in European countries. Later it has widened its extent involving the females also. And in the recent days it has emerged as a fashion accessory both in males and females. ${ }^{1}$

Earlier to the origin of the word tattoo in the western countries it was described as painting, scarring or staining. The word tattoo is also called as a tattoo in the early period of its birth. Tatau is a Polynesian word which means "to write". In the literature, tattoo was first described in the journal of Joseph Banks in 1743. ${ }^{2}$

As per the American Academy of Dermatology, tattoos have been classified into 5 categories. 1. Natural tattoo/Traumatic tattoo; 2. Amateur tattoo; 3. Professional created tattoo includes both local and advanced technology being used; 4. Cosmetic tattoos / Permanent and last one is 5. Medical tattoo. ${ }^{3}$

The usage of tattoos in the identification of burned and decomposed and mutilated body is widely used in forensic investigations. As the material used in tattoos may also give the clues for investigation in mutilated bodies. ${ }^{4}$

Most of the studies on the tattoos in the literature search were found to be either dermatological complications or other physical related issued which are being surfaced in the scholarly articles. Among these, the article which has been mentioned about the cutaneous allergic reactions to the material used are common. ${ }^{6}$

\section{Objectives}

To know the prevalence of tattoo,

To assess the religion and gender-wise distribution,

To know the reasons for getting a tattoo and

After effects of tattooing. 


\section{Materials and Method}

All the individuals from the society with whom the researcher come in contact having tattoos. A proforma was prepared for the same with the standard questionnaire and asked the individuals to fill the same. The researcher will help in filling the form for illiterates; since the answer to the questions are specific standard replies.

\section{Results}

Among 101 individuals 90 were Hindu, 6 Muslim and 5 Jain were present. In the study population number of females (55) were participated whereas males(46). 79 participants were from Urban area and 22 were from rural backup.

Table 1: Marital status

\begin{tabular}{|l|c|c|}
\hline & Frequence & Percentage \\
\hline Married & 42 & 41.6 \\
\hline Unmarried & 59 & 58.4 \\
\hline & 101 & 100.0 \\
\hline
\end{tabular}

When we looked at the educational status of the individuals participated in the more people (30) were studying intermediate schooling followed by 24 in primary schooling.

And this was followed by 18 illiterates and 11 who passed Pre University College. 12 were graduates and 6 were just able to read and write their names.

In the study group, maximum number was constituted by students (47) followed by semiskilled (36) and 12 labor workers with least number of house wives(6).

54 subjects have the permanent tattoos and 47 were having temporary in nature.

Table 2: Method used for tattooing

\begin{tabular}{|l|c|c|}
\hline Methods & Frequency & Percent \\
\hline Needling & 54 & 53.5 \\
\hline Spray & 18 & 17.8 \\
\hline Sticker & 29 & 28.7 \\
\hline Total & 101 & 100 \\
\hline
\end{tabular}

The nature of applying tattoo was more in needling(54) followed by sticker(29) and least with spray(18)

90 individuals have paid for getting tattoo done and 11 have got it done free of cost.
Table 3: Site of Tattoo

\begin{tabular}{|l|c|c|}
\hline Site & Frequency & Percent \\
\hline Hands & 71 & 70.3 \\
\hline Legs & 6 & 5.9 \\
\hline Neck & 12 & 11.9 \\
\hline $\begin{array}{l}\text { Neck, Shoulder, Arm, } \\
\text { Hands \&Legs }\end{array}$ & 6 & 5.9 \\
\hline Shoulder, hands, legs & 6 & 5.9 \\
\hline Total & 101 & 100 \\
\hline
\end{tabular}

Looking at the site of the tattoo being applied hand (71) has taken the upper hand with almost $70 \%$ followed by the neck (12) of about $11.9 \%$ and 6 individuals in the each group of the complete leg, complete legs, hands and shoulder and Neck, shoulder, arms, hands, and legs. Among 101 individuals 71 had single coloured tattoo whereas 30 had more than one colour is used.

Table 4: Size of the tattoo

\begin{tabular}{|l|c|c|}
\hline Body size & Frequency & Percent \\
\hline Hand & 71 & 70.3 \\
\hline Legs & 6 & 5.9 \\
\hline Neck & 12 & 11.9 \\
\hline $\begin{array}{l}\text { Upper \& Lower } \\
\text { limb }\end{array}$ & 12 & 11.9 \\
\hline Total & 101 & 100 \\
\hline
\end{tabular}

Table 5: Reason for getting tattoo

\begin{tabular}{|l|c|c|}
\hline Reason & Frequency & Percent \\
\hline Fashion & 47 & 46.5 \\
\hline No meaning & 18 & 17.8 \\
\hline Other & 6 & 5.9 \\
\hline Passion & 24 & 23.8 \\
\hline Religious & 6 & 5.9 \\
\hline Total & 101 & 100 \\
\hline
\end{tabular}

Reason for getting a tattoo done was also analyzed in this study where 47 people claimed it is as fashion followed by 24 as passion. 18 were having no meaning in getting the tattoo done where 6 individuals claimed the religious region and other 6 did not say any answer for the same.

Amateur induced tattooing was 50 in number compared to professional which was about 25 and 26 were got a tattoo done by themselves. Our study tried to analyze the complaints after getting the tattoo done; 83 of them did not complain anything where as 6 subjects have complained burning, dry skin, and itching in each group. We also tried to look whether the subjects are planning to get rid of this tattoos; 89 subjects have told no and 12 subjects were planning to get removed. The way of removal was also considered as one of the parameters; 71 have said it's not possible to 
remove; 24 have said that it will get removed naturally and 6 have considered of removing it by washing.

Table 6: Regrets after tattoo

\begin{tabular}{|l|c|c|}
\hline Regrets & Frequency & Percent \\
\hline No & 81 & 80.2 \\
\hline Yes & 20 & 19.8 \\
\hline Total & 101 & 100 \\
\hline
\end{tabular}

\section{Discussion}

The study included totally 101 individuals, of which 90 were Hindu, 6 Muslim and 5 Jain were present. Since the study was conducted in a place where the majority of Hindus live and this may not give any statistical significance with respect to religion. And also there was no much research work done on this while doing the literature search online. In the study population number of females (55) were participated whereas males(46). This shows that male to female ratio is almost equal in number. 79 participants were from Urban area and 22 were from rural backup. This is basically because the study was conducted in the rural setup; where the interior of the village side has not been covered widely.

When we looked at the educational status of the individuals participated in the more people (30) were studying intermediate schooling followed by 24 in primary schooling. And this was followed by 18 illiterates and 11 who passed Pre University College. 12 were graduates and 6 were just able to read and write their names.In the study group, maximum number was constituted by students (47) followed by semiskilled(36) and 12 labor workers with least number of house wives (6). In one of the studies done by Armstrong has mentioned that there is no correlation between having tattoo and its educational status. $^{7}$

54 subjects have the permanent tattoos and 47 were having temporary in nature. The nature of applying tattoo was more in needling (54) followed by a sticker (29) and least with spray (18). 90 individuals have paid for getting a tattoo done and 11 have got it done free of cost.

Looking at the site of a tattoo being applied hand(71) has taken the upper hand with almost $70 \%$ followed by the neck(12) of about $11.9 \%$, and 6 individuals in the each group of the complete leg, complete legs, hands and shoulder and Neck, shoulder, arms, hands and legs.

Among 101 individuals 71 had single coloured tattoo whereas 30 had more than one colour is used. Reason for getting a tattoo done was also analyzed in this study where 47 people claimed it is as fashion followed by 24 as passion. 18 were having no meaning in getting the tattoo done where 6 individuals claimed the religious region and other 6 did not say any answer for the same.

In one of the studies as the sample subjects had negative thoughts towards those who had tattoos also had positive views towards those who had tattoos. Those who had negative

Thoughts looked tattooed individuals are more of Crude, Foolish, Immoral, Unstable and Undesirable. And those tattooed individuals in a positive viewed were seen as Desirable, Enjoyable, Interesting, Self-confident, Progressive and Unique. ${ }^{7}$

Amateur induced tattooing was 50 in number compared to professional which was about 25 and 26 were got a tattoo done by themselves. Our study tried to analyze the complaints after getting the tattoo done; 83 of them did not complain anything where as 6 subjects have complained burning, dry skin, and itching in each group. We also tried to look whether the subjects are planning to get rid of this tattoos; 89 subjects have told no and 12 subjects were planning to get removed.

The way of removal was also considered as one of the parameters; 71 have said it's not possible to remove; 24 have said that it will get removed naturally and 6 have considered of removing it by washing. And 20 individuals were regretting to have these tattoos being done and remaining have not felt the same.

\section{Conclusion}

The study was undertaken to know the widespread increase in the tattoo being done on individuals. Here the urban area and literacy rate has some significant comparison with the available literature. Otherwise, the other components considered in this study are unique to its gender and unmarried people were slightly higher than the married. In this study students have more tendency compared to another group. And number had a permanent tattoo with a single colour. Hands are the commonest site for tattoo and fashion is the main reason. Amateur done tattoo was more with no complaints after getting the tattoo done. Majority of the people have no plans to get the tattoo removed and less number of subjects were regretting getting the tattoo done. 


\section{References}

1. Caplan, Jane (ed.) (2000): Written on the Body: the Tattoo in European and American History, Princeton University Press.

2. Sir Joseph Banks, Baronet. Britannica.com. Retrieved on 22 June 2017.

3. "Tattoos, Body Piercings, and Other Skin Adornments". Aad.org. Retrieved 5 April 2012.

4. Small, Richard. "Review of livestock identification and traceability in the UK" (PDF). GOV.UK. DEFRA, Farm Animal Genetic Resources Committee. Retrieved 17 March 2017.

5. Joshua Adams (2012), "The Relationship between Tattooing and Deviance in Contemporary Society", Deviance Today, pp. 137-145.

6. Tattoos: Risks and precautions to know first". MayoClinic.com. 20 March 2012. Retrieved 5 April 2012.

7. Armstrong, M. L., Owen, D. C., Roberts, A. E., \& Koch, J. R. (2002). College students and tattoos: Influence of image, identity, family, and friends. Journal of Psychosocial Nursing \& Mental Health Services, 40(10), 20-9. Retrieved from http://ezproxy.rit.edu/login?url=http://search.proq uest.com/docview/225539336? accountid=108. 